\title{
DISGUSSION
}

\section{SUSPENSION, EQUIPOLLENGE, AND INQUIRY: A REPLY TO WIELAND}

\author{
DIEGO E. MACHUCA \\ Consejo Nacional de Investigaciones Científicas y Técnicas
}

\section{Introduction}

It is generally thought that suspension of judgment about a proposition $p$ is the doxastic attitude one is rationally compelled to adopt whenever the epistemic reasons for and against $p$ are equipollent or equally credible, that is, whenever the total body of available evidence bearing on $p$ epistemically justifies neither belief nor disbelief in $p$. However, in a recent contribution to this journal, Jan Wieland proposes "to broaden the conditions for suspension, and argue that it is rational to suspend belief on a certain issue even if one's current evidence is not neutral (or even close to neutral)" (2014: 222). My aim in this paper is to point to a number of problems in Wieland's position, some of which in connection with the account of Pyrrhonian skepticism found in the extant works of Sextus Empiricus.

The reason for mentioning Pyrrhonian skepticism is that it figures prominently in Wieland's paper. He remarks that his approach is systematic, and hence that the attitude of suspension he is concerned with "may differ in some respects from the attitude Sextus had in mind" (2014: 224) and that he does "not aim to contribute to the reading of Sextus' works" (2014: 226). However, as we will see below, Wieland's classification of the different motivations for suspension of judgment is drawn from Sextus's account of Pyrrhonism, and the main argument he advances is based on an argument he thinks is found in Sextus. It is therefore legitimate to argue, as I do, that the kind of skeptical position whose rationality Wieland defends is not compatible with anything one finds in Sextus. My reason for so doing is not only that it is historically and exegetically important to have an accurate picture of Pyrrhonism as it is described in Sextus's surviving writings, but also that, from a systematic point of view, it is important not to distort some of the defining features of Pyrrhonism considered as a philosophical stance that is still worth exploring in its own right - and that has in fact been a focus of considerable attention in contemporary epistemology. This said, I will also concern myself with the rationality of the skeptical position described by Wieland independently of its relation with Sextan Pyrrhonism. I will therefore deal with 
two issues: whether one finds in Sextus what Wieland calls "the argument from inquiry" and whether such an argument is sound or plausible - the verdict being in both cases negative. I intend to show that the claim that suspension about a proposition $p$ can be attained even if the evidence for and against $p$ is not equipollent or equally strong is both exegetically and philosophically incorrect.

In Sections II and III, I will look at the three reasons for suspending judgment that Wieland claims to find in Sextus, focusing in Section III on Wieland's argument from inquiry. In Section IV, I will explore Wieland's taxonomy of skeptics and dogmatists and the corresponding taxonomy of principles of epistemic rationality.

\section{The Reasons for Suspension}

Wieland (2014: 223) claims that in Sextus's works one finds three motivations or reasons for suspending our beliefs:

(a) we cannot justify them,

(b) doing so is necessary for the good life, and

(c) doing so is necessary for inquiry.

In this section, I will look at the connection between suspension and reasons (a) and (b), while the connection between suspension and reasons (a) and (c) will be tackled in the next section in the examination of Wieland's argument from inquiry.

It must first be noted that, with reason (b), Wieland is referring to Sextus's remark that, when the Pyrrhonist suspended judgment about all the non-evident matters he had investigated, there followed unexpectedly or fortuitously the state of tranquility or undisturbedness (ataraxia), which was the aim he was seeking to attain (Pyrrōneioi Hypotypōseis [PH] I 26, 29, 205).

Secondly, in making the above distinction between three motivations for suspension, Wieland fails to distinguish between motivations and causes, and hence fails to realize that (a), (b), and (c) are not on a par. Sextus presents (a) as a cause - in fact, as the only cause - of suspension of judgment, not as a motivation for it. For example, when explaining the sense of the Pyrrhonian phrase "I suspend judgment," he points out:

We use "I suspend judgment" in lieu of "I cannot say which of the things proposed I ought to believe and which I ought to disbelieve," thereby making it clear that objects appear to us equal in respect of credibility and lack of credibility. (...) Suspension of judgment is so called from the fact that the intellect is suspended so that it neither posits nor rejects anything due to the equipollence of the matters investigated. $(P H \text { I 196 })^{1}$

1. The translations of $P H$ are mine, but I have consulted Annas and Barnes (2000), Bury (1933), and Mates (1996). 
Nothing of what Sextus says in this passage, or anywhere else in his extant writings, supports the view that, at least in certain cases, the Pyrrhonist suspends judgment about $p$ because he wants to either remain undisturbed or continue his inquiries, even though the reasons for and against $p$ do not appear to him equipollent or equally credible. Given his past experience, the Pyrrhonist may expect that undisturbedness will continue to follow upon his suspension of judgment about everything, and so, if undisturbedness continues to be an aim he wants to achieve, this will be a motivation for suspending judgment. This motivation, however, does not suffice to bring about suspension of judgment, which is induced or caused in the Pyrrhonist only when conflicting claims or arguments strike him as equipollent. For this reason, I can only partially agree with Wieland when he maintains:

Importantly, (c), just like (b), is a positive reason for suspension, and does not depend on the success of the negative reason (a). That is, it purports to show that suspension is a good thing even if Agrippa's modes fail, i.e., even if it is possible to justify some of our beliefs. (2014: 225)

It is plain that one may have a pragmatic reason for adopting a given doxastic attitude even if one has no epistemic reason for so doing. However, the fact that suspension may be something valuable for pragmatic reasons in no way entails that it can be induced even if the total body of available evidence tips the balance in favor of one of the conflicting claims or arguments. This is why one should distinguish what we might call a 'motivation' for suspension of judgment from its cause: while (b) has been up to now a motivation for suspending judgment, (a) is the cause for so doing, and so, pace Wieland, (a) and (b) are not on a par.

\section{Suspension and Ongoing Inquiry}

What about (c) as a reason for suspending judgment? Wieland concludes that "it is rational to suspend one's belief regarding p so long as one is open to investigating p . . . even if one has, at the moment, more evidence for or against p" (2014: 234-235) on the basis of what he calls "the argument from inquiry," which he thinks (2014: 227) is found in the following two Sextan passages. ${ }^{2}$ In the first, Sextus is distinguishing between three kinds of philosophy, while in the second he is responding to the objection that the Pyrrhonist, because of his suspension of judgment, cannot investigate what the dogmatists ${ }^{3}$ talk about:

For those who investigate any matter, the likely result is either a discovery, or a denial of discovery and an admission of inapprehensibility, or a

2. I will here quote more extensive versions of the two passages because the portions quoted by Wieland make it quite difficult to understand Sextus's line of thought.

3. It should perhaps be reminded that, although a "dogmatist" for Sextus is someone who is arrogant and makes rash judgments, it is not someone who makes assertions about how things are without offering any reasons, but on the basis of what he considers to be objective evidence and sound arguments. 
continuation of the investigation. This is perhaps why, also with regard to the matters investigated in philosophy, some have said that they have discovered the truth, some have affirmed that it cannot be apprehended, and others are still investigating. Those called dogmatists in the proper sense of the term think that they have discovered it . . C Clitomachus and Carneades and other Academics have affirmed that it concerns things that are inapprehensible. And the skeptics are [still] investigating. ( $P H$ I 1-3)

And consider whether even in this case the dogmatists are not debarred from investigation. For to continue to investigate the objects is inconsistent, not for those who agree that they ignore how they are in their nature, but for those who think that they know them accurately. Indeed, for the latter, the investigation has already arrived at its end, as they suppose, whereas for the former, the reason why all investigation is undertaken - the thought that they have not made a discovery-still exists. (PH II 11)

What is surprising about Wieland's reading of these passages is that in them one finds nothing remotely close to the view that one is entitled to suspend judgment about $p$ provided one is open to inquiring further into $p$, even if the reasons for and against $p$ do not strike one as equipollent. Moreover, PH II 11 makes it entirely clear that the Pyrrhonist's reason for suspending judgment is not that he wants to continue his inquiry into truth, but that as yet he has not found the answer to the question, what is the nature of $x$ ? And the reason why he does not know the answer to that question (and hence suspends judgment) is that the rival views he has so far examined on the matter appear to him to be equally persuasive or credible. The relation between suspension and ongoing inquiry is not therefore that the Pyrrhonist suspends judgment about certain questions because he wants to continue to investigate them, but the reverse: he continues to investigate certain questions because he suspends judgment about them, and he suspends judgment about them because the conflicting views on them strike him as equipollent. In other words, since equipollence has kept him from making up his mind regarding the matters he has inspected, he continues his inquiry into those matters. From the alleged fact that one can (continue to) inquire into $p$ only if one suspends judgment about $p$, it does not follow that one suspends judgment about $p$ because one wants to (continue to) inquire into $p$. Suspension of judgment about $p$ makes possible the continuation of the inquiry into $p$, but this is completely different from saying that it is the means to the end of continuing to inquire into $p$. Hence, (c) is not the basis of suspension; only (a) is. Moreover, unlike (b), (c) cannot be taken to be a motivation for suspension, for Sextus does not present suspension as a means for attaining the aim of investigation.

So the conclusion of Wieland's argument from inquiry is not found in Sextus for the simple reason that the latter never claims that it is rational to suspend judgment about $p$, even if the available evidence supports $p$ or its negation, provided one is open to inquiring further into the truth of $p$. But what are the premises of such an argument? They are to be found in the following considerations made by Wieland toward the end of his paper: 
If $\mathrm{S}$ has [a serious] interest [in the truth about $\mathrm{p}$ ], then it is plausible to think that she must aim to avoid holding inadequately examined beliefs about $\mathrm{p}$ and if so, $\mathrm{S}$ must be open to the possibility that her actual evidence about p requires further attention. Now, in such circumstances where $S$ is awaiting the outcome of further inquiries, i.e., awaiting new evidence of which $\mathrm{S}$ does not know yet what it will support, it is appropriate for $\mathrm{S}$ to adopt a neutral and impartial attitude. That is, in such circumstances it is appropriate to suspend in the meantime, and less appropriate to stick to beliefs (even beliefs that do, indeed, enjoy widespread support at the moment). Hence, by transitivity: If $\mathrm{S}$ has a serious interest in the truth about $\mathrm{p}$, then, even if at the moment she has more evidence for or against $\mathrm{p}, \mathrm{S}$ should suspend her belief about p.

Consider, for example, the proposition that nothing travels faster than light. This proposition (and hence the belief in it) enjoys widespread support despite some disconfirming and non-robust experimental results. Now the question is what attitude to adopt if you are really interested in the truth of the matter. (...) You can either provisionally believe that nothing travels faster than light, or provisionally suspend belief in it. The argument just given for the second option admits that it is possible to believe in such circumstances, yet concludes that it is still more appropriate to suspend for inquiry-related reasons. Namely, if you are awaiting the outcome of further inquiries, it is appropriate to adopt a neutral and impartial attitude, which is exactly the attitude of suspension. (2014: 233-234)

I must confess that I do not understand how it may be more rationally appropriate to suspend judgment about $p$ than to (provisionally) believe that $p$ when the total body of evidence available at time $t$ supports $p$ to a (much) greater extent than it supports not- $p .{ }^{4}$ As far as I can see, it would be rational to suspend judgment in such a situation only if one could construct, on the basis of the considerations about the possible defeating results of future inquiries, an argument that counterbalances the current evidence in favor of $p$. Interestingly, a maneuver of this kind is found in Sextus, who appeals to an argument based on the possibility of future disagreement in order to counterbalance an argument on a given topic to which at present he cannot oppose an equally credible argument on the same topic (see PH I 33-24, 89, 143; II 40-41 [cf. II 61]; III 233-234). Consider the following passage:

Whenever someone propounds to us an argument that we are not able to refute, we say to him: "Just as before the birth of the founder of the school to which you belong, the argument of the school, which is sound, was not

4. Wieland's example about the speed of light is not particularly felicitous, given that all available evidence supports the proposition that nothing travels faster than light in a vacuum. It has been reported that the results of the experiments of the OPERA team at Geneva's CERN laboratory that indicated that neutrinos travel faster than light were due to the fact that the measuring equipment was flawed. 
yet apparent, but was nonetheless really there in nature, so likewise it is also possible that the argument opposing the one you are propounding now is really there in nature, but that it is not yet apparent to us, so that we should not yet assent to what now seems to be a strong argument." (PH I 33-34)

It might seem that this argument, which I have elsewhere called "the argument from possible disagreement," proves that after all we do find the argument from inquiry in Sextus, albeit not where Wieland claims one does. For Sextus can be taken to be saying that one should not assent to the conclusion of an undefeated argument for $p$ because, through further inquiry, one might discover an argument against $p$ that defeats it. However, a crucial difference between Sextus and Wieland is that the former refers to opposing arguments: one needs an opposition between equally strong arguments for and against $p$ in order to withhold assent to $p$ or suspend judgment about $p$. Moreover, the opposition must be actual and not merely possible; otherwise, there would be no equipollence. This is why I have elsewhere argued that, in the passages in which Sextus appeals to the argument from possible disagreement, suspension of judgment is the result of the opposition, not of the current argument for $p$ and the argument against $p$ that might be discovered in the future, but of the argument for $p$ and the argument from possible disagreement itself, both of which at present strike the Pyrrhonist as equally credible (see Machuca 2011 a: sect. II; Forthcoming: sect. 3). Similarly, in the case of the argument based on the ignorance about the outcome of further inquiries, the only compelling reason one might have for suspending judgment about $p$ is not that one is open to investigating further the truth of $p$, but that the argument in favor of $p$ is set in opposition to the argument from inquiry and both strike one as equally strong or credible. One could argue that, in putting forward the above considerations about the possible defeating results of future inquiries, Wieland is recognizing malgré lui that, in order to suspend judgment about $p$ when the available evidence favors $p$ over not- $p$, it does not suffice to be interested in inquiring further into the truth of $p$, but one needs countervailing evidence against $p$. Hence, recalling the three reasons for suspension distinguished by Wieland, the reason for suspending judgment is not once again (c), but (a).

Finally, it might be useful to imagine what a dogmatist's reaction would be if he were confronted with a skeptic who claimed that the dogmatist should suspend judgment about $p$ if he is open to investigating further the truth of $p$, no matter whether his total body of available evidence presently supports either $p$ or not- $p$. The dogmatist would be within his rights to dismiss out of hand such a claim. For even though the skeptic agrees with the dogmatist that the total body of available evidence does support either $p$ or not- $p$, the dogmatist is asked to accept that it is nonetheless rational to suspend judgment about $p$. Wieland's argument from inquiry is entirely ineffective against the dogmatist because it does not require that the skeptic offer reasons that show that the dogmatist's total body of available evidence actually supports neither $p$ nor not- $p$. 


\section{Four Principles of Rationality}

Wieland (2014: 229) distinguishes between positive and negative skepticsi.e., between those who "do not admit beliefs (even if the evidence supports them) and are (open to) investigating" and those who "do not admit beliefs, and are not (open to) investigating"-and between positive and negative dogmatists - i.e., between those who "admit beliefs (if supported by the evidence) and are (open to) investigating" and those who "admit beliefs and are not (open to) investigating." According to Wieland, each of these four types of persons is committed, respectively, to the following four principles of epistemic rationality:

\section{Suspend+}

$\mathrm{S}$ epistemically should suspend her belief about $\mathrm{p}$ at $\mathrm{t}$ so long as $\mathrm{S}$ is open, at $t$, to considering new evidence regarding $\mathrm{p}$ at $\mathrm{t}^{*} /$ gathering new evidence regarding $\mathrm{p}$ at $\mathrm{t}$.

\section{Suspend-}

$\mathrm{S}$ epistemically should suspend her belief about $\mathrm{p}$ at $\mathrm{t}$, no matter what her evidence for or against $\mathrm{p}$ at $\mathrm{t}$, or any other $\mathrm{t}^{*}$.

\section{Stick+}

S epistemically should stick to her belief about $\mathrm{p}$ at $\mathrm{t}$, which is supported by her evidence at $\mathrm{t}$, yet be open, at $\mathrm{t}$, to changing her position in the light of new evidence regarding $\mathrm{p}$ at $\mathrm{t}^{*} /$ that one is gathering regarding $\mathrm{p}$ at $\mathrm{t}$.

\section{Stick-}

$\mathrm{S}$ epistemically should stick to her belief about $\mathrm{p}$ at $\mathrm{t}$, and never change position in the light of new evidence regarding $\mathrm{p}$ at $\mathrm{t}^{*} /$ never gather new evidence regarding $\mathrm{p}$ at $\mathrm{t}$ or any other $\mathrm{t}^{*}$. (2014: 231)

Wieland remarks that his

claim is not that Pyrrhonism, or Sextus' scepticism, is best considered as a 'Positive Scepticism'. (I am tempted to think this to some extent, yet in the remainder of this paper I shall elaborate this view in a way that goes beyond the letter of Sextus' writings.) Rather, my claim is that Sextus did not distinguish clearly between Positive and Negative Dogmatists. For Positive Dogmatism is exactly the view that combines belief (i.e., provisional belief) with investigation. (2014: 229)

Several remarks about Wieland's taxonomies are in order. First of all, despite his hesitation, there is no doubt that not only Sextus's presentation of Pyrrhonism but also Pyrrhonian skepticism considered as a philosophical stance are incompatible with positive skepticism: if the total body of available evidence supports $p$ over not- $p$ at $t$, then at $t$ there is no equipollence or equal credibility between the conflicting views about the truth of $p$. If the evidence tells one that $p$ is the case, there is no equipollence, and if there is no equipollence, there is no suspension of judgment, since, once again, the very basis of suspension is the equal strength of the reasons for and against $p$. Another 
reason for claiming that positive skepticism is incompatible with Pyrrhonism is that the former is based on Suspend+, for Pyrrhonian suspension of judgment does not rest on a commitment to some rational principle or norm. Some interpreters have indeed claimed that the Pyrrhonist's suspension is the result of the adherence to a norm according to which one is rationally required to suspend judgment about whether $p$ if it appears to one that there is no reason to either believe or disbelieve $p$ (see esp. Perin 2010: ch. 2). But in line with most interpreters, I think that suspension should rather be construed as the result of a psychological constraint: suspension is the involuntary psychological effect of being confronted with arguments that strike one as equally persuasive. Given that the Pyrrhonist is a thinking being (PH I 24) who is hardwired to respond in specific ways, he is affected by the consideration of arguments pro and con $p$ and automatically reacts in a given way, even though he refrains from making assertions about both whether those arguments are sound and whether they are objectively equipollent (see Machuca 2011 b: sect. 5; 2013: sect. 4).

Secondly, I agree with Wieland (2014: 227-228) - and Barnes (2007: 323324 - that it is possible to combine provisional or tentative belief with investigation: one may hold the belief that $p$ and continue to investigate its truth because one may hold the belief that $p$ without being fully certain that $p$ is true. ${ }^{5}$ What I do not understand is how Wieland can claim that a person whose evidence supports the belief that $p$ to, say, a 0.7 degree may nonetheless rationally suspend judgment about $p$. If one's total body of available evidence favors $p$ over not- $p$ but not conclusively or with full certainty, then it seems that one is rationally compelled to hold the belief that $p$, even if less confidently than one would if one were fully certain of the truth of $p$. And one may do so while being fully aware that further evidence might defeat one's current reasons for holding the belief that $p$. In fact, something like this is what fallibilists - i.e., most present-day epistemologists - propose when they claim that no belief can ever be epistemically justified in a conclusive way.

Thirdly and relatedly, if one accepts Wieland's defense of the rationality of positive skepticism, one will have to accept the unintuitive view that one is rational even when there is a conflict between one's evidence or reasons regarding $p$ and one's doxastic attitude toward $p$. For provided that one is open to investigating further the truth of $p$, one is entitled to suspend judgment about $p$ even if one's evidence supports $p$ to a degree of credence above or below 0.5. Wieland's positive skeptic is blind to the evidence.

Fourthly, it should be noted that the formulation of Suspend-brings the negative skeptic very close to the positive skeptic, for according to Wieland's characterization of the latter, the positive skeptic suspends judgment about $p$ at $t_{1}$ even though the evidence supports the belief that $p$ at $t_{1}$. Moreover, one might wonder whether the positive skeptic is really open to considering new evidence bearing on $p$ at $t_{2}$, for it seems that even if at $t_{2}$ the evidence supported the belief

5. In a partial defense of Sextus, it should be noted that, at PH I 2, he talks of those who claim to have discovered the truth, which is to be understood in the sense that they claim to have apprehension or certain knowledge of the truth. And at PH II 11, he talks of those who claim to know accurately how things are by nature. 
that $p$, he would still suspend judgment about $p$ because he will be open to considering new evidence at $t_{3}$, and so on. If this is correct, then in the final analysis there seems to be no difference between the positive and the negative skeptics not only regarding their attitudes toward the evidence available at $t_{1}$, but also toward the evidence available at any other $t^{*}$. One can thus question the positive skeptic's genuine interest in discovering the truth. The correctness of this objection seems to be confirmed by Wieland's following remarks:

To see more clearly the differences among these principles, let us consider a scenario. Suppose that $S$ 's evidence at a time $t_{1}$ supports $\sim p$ (in terms of degrees, $S$ 's evidence at $t_{1}$ indicates to $S$ that the likelihood of $p$ is, say, 0.3). Suppose furthermore that if $\mathrm{S}$ were open to further evidence about $\mathrm{p}$, then her evidence at a subsequent time $t_{2}$ would in fact support $\mathrm{p}$ (in terms of degrees, $S$ 's evidence at $t_{2}$ would indicate to $S$ that the likelihood of $p$ is 0.7 ). Of course, if she is not open to this further evidence, then her evidence at $t_{2}$ would still support $\sim p$ (and indicate a likelihood of 0.3 ). We may ask: What doxastic attitude should $\mathrm{S}$ adopt at $\mathrm{t}_{2}$ according to the four principles in this scenario? (2014: 231)

In Wieland's view, the doxastic attitude to be adopted by both the positive and the negative skeptics at $t_{2}$ is suspension, that of the positive dogmatist is belief, and that of the negative dogmatist is disbelief. So at $t_{2}$, the positive skeptic suspends judgment about $p$ even though his evidence supports $p$ to a 0.7 degree, and although Wieland does not say so, we may assume that at $t_{1}$ the positive skeptic also suspends judgment about $p$ even though the evidence supports $p$ to a 0.3 degree. So it seems that the positive skeptic is actually immune to what his evidence might support at any given time. Nonetheless, Wieland surprisingly maintains that only the positive skeptic and the positive dogmatist are interested in truth, whereas the negative dogmatist and the negative skeptic are not, on the following grounds:

Suppose that a Negative Dogmatist believes p. In that case, she would stick to $\mathrm{p}$ even if her new evidence supports $\sim \mathrm{p}$. This conflicts, however, with the interest in truth, for if you are really interested in the truth of $\mathrm{p}$, you should not believe $\mathrm{p}$ in the face of a preponderance of evidence against it.

(. . .) Suppose that all the evidence available to a Negative Sceptic supports p. In that case, Negative Sceptics will neglect all this evidence and suspend. This, again, is in conflict with an interest in truth, for if one is interested in the truth of p, one should not ignore relevant evidence. (2014: 231-232)

So the negative dogmatist and the negative skeptic are accused of not being interested in the truth of $p$ because they neglect the evidence, i.e., the doxastic attitudes they adopt toward $p$ are indifferent to what the available evidence supports. How is this different from what the positive skeptic does? Moreover, it seems that the negative skeptic proceeds rationally whereas the positive skeptic does not insofar as the former dismisses the evidence because he rules out the possibility that the truth can ever be found or known. It is not so much 
that the negative skeptic is not interested in truth, but that he believes he has an argument, or set of arguments, that establishes that the truth about the matters under investigation cannot be found and that defeats any evidence he might come across. By contrast, despite lacking any such argument, when faced with evidence that supports the belief that $p$ or the belief that not- $p$, the positive skeptic still suspends judgment about $p$, when it seems that he should rather hold the belief supported by the available evidence and hence stop being a skeptic. In the absence of any defeating reasons, in such an epistemic situation it seems irrational to suspend judgment. Suspend+ would recommend a rational way of responding to the evidence only if it claimed that one should suspend judgment if there is no reason for believing either $p$ or not- $p$.

I would like to conclude by considering an objection raised by a reviewer. $\mathrm{He} /$ she has argued that my claim that the positive skeptic cannot be interested in truth because his doxastic attitude will not be affected by new evidence seems to rest on the following principle:

If one's doxastic attitude regarding $p$ will not be affected by new evidence regarding $p$, then one is not interested in $p$ 's truth.

According to the reviewer, the problem is that this principle is in tension with Wieland's distinction between doxastic and inquisitive attitudes, and with his claim that one is interested in $p$ 's truth whenever one has an inquisitive attitude toward $p$. As I have argued, Wieland's distinction between doxastic and inquisitive attitudes is problematic because inquiry into the truth of $p$ makes sense only if one's doxastic attitude is responsive to the total body of available evidence regarding $p$. Given that Wieland's positive skeptic is immune to what the evidence establishes both at time $t$ and at any other $t^{*}$, what is the point of his inquiring? If the positive skeptic continues to suspend judgment even if the total body of available evidence $\mathrm{E}$ supports either $p$ or not- $p$ at $t$, and will continue to suspend judgment even if $\mathrm{E}$ will support either $p$ or not- $p$ at any other $t^{*}$, what does his inquiry into the truth of $p$ consist in? It seems that such an inquiry is a priori doomed to failure, for the positive skeptic will continue to suspend judgment about $p$ no matter what the evidence supports. It should finally be noted that Wieland himself endorses the principle in question, since in the quoted passage above he accuses the negative dogmatist and the negative skeptic of not being interested in the truth of $p$ because the doxastic attitudes they adopt toward $p$ are indifferent to what the total body of available evidence supports. ${ }^{6}$

\section{References}

Annas, J. and J. Barnes. 2000. Sextus Empiricus: Outlines of Scepticism. 2nd edition. Cambridge: Cambridge University Press.

6. My thanks to an anonymous reviewer for his/her critical remarks on a previous version of this paper. 
Barnes, J. 2007. "Sextan Pyrrhonism." In D. Scott (ed.), Maieusis: Essays on Ancient Philosophy in Honour of Myles Burnyeat, 322-334. Oxford: Oxford University Press.

Bury, R. G. 1933. Sextus Empiricus: Outlines of Pyrrhonism. Cambridge, MA: Harvard University Press.

Machuca, D. 2011 a. "The Pyrrhonian Argument from Possible Disagreement," Archiv fü Geschichte der Philosophie 93: 148-161.

Machuca, D. 201 lb. "Pyrrhonism and the Law of Non-Contradiction." In D. Machuca (ed.), Pyrrhonism in Ancient, Modern, and Contemporary Philosophy, 51-77. Dordrecht: Springer.

Machuca, D. 2013. "Pyrrhonism, Inquiry, and Rationality," Elenchos 34: 201-228.

Machuca, D. Forthcoming. "Again on Sextus on Persuasiveness and Equipollence," Archiv für Geschichte der Philosophie.

Mates, B. 1996. The Skeptic Way: Sextus Empiricus's Outlines of Pyrrhonism. New York: Oxford University Press.

Perin, C. 2010. The Demands of Reason: An Essay on Pyrrhonian Scepticism. Oxford: Oxford University Press.

Wieland, J. 2014. "Sceptical Rationality,” Analytic Philosophy 55: 222-238. 